\title{
Training Needs Assessment at Assir General Educational Directorate, Saudi Arabia
}

\author{
Ikhlas I. Altarawneh ${ }^{*}$, Amal Ibrahim Ahmed Aseery ${ }^{2}$ \\ ${ }^{1}$ Department of Business Administration, College of Business and Economics, Al-Hussein Bin Talal University, \\ Ma'an, Jordan \\ ${ }^{2}$ Al-Faisal University, Abha, KSA \\ Email: "Ikhlas2010@yahoo.com, Dr.ikhlas@ahu.edu.edu.jo,specialrose21@hotmail.com
}

Received 14 January 2016; accepted 26 February 2016; published 29 February 2016

Copyright (C) 2016 by authors and Scientific Research Publishing Inc.

This work is licensed under the Creative Commons Attribution International License (CC BY). http://creativecommons.org/licenses/by/4.0/

(c) (;) Open Access

\section{Abstract}

The aim of the current study is to explore the current management and practices for Training Needs Assessment (TNA) process at Assir General Educational Directorate (AGED) in Abha, Saudi Arabia. It aims also to shed the light on the most important concerns, problems, and challenges that face Training and Development ( $\mathrm{T} \& \mathrm{D}$ ) processes and programs and to propose practical suggestions and recommendations to improve TNA process and practices and overcome T \& $D$ problems and challenges in AGED. The study adopted the quantitative deductive approach through a survey research strategy. A self-administrated questionnaire which was constructed based on previous studies was the main data collection method used to capture the data from almost all the administrative female supervisors (70) working at AGED. The findings of this study show that: in spite of the importance of identifying and assessing training needs of individuals, the majority of the study participants have never identified training needs for the people that they supervise. They do not rely on systematic techniques when identifying trainees; however, they use their own subjective manners. Moving individuals from one work place to another; low morale of individuals; students' dissatisfaction; increasing complains and lack of skills were among the most important indicators of training needs. Lectures, guidance and supervision, group discussions and practical show were the most common $T \& D$ techniques and used methods. Main challenges of $T \& D$ were: the inability to identify training needs, insufficient numbers of qualified training centers, lack of motivation to participate in $T \& D$ because of the lack of support from the external environment such as (family, friends, etc.) and lack of time and budget to support the training processes. The study has made significant contributions to the body of knowledge at academic and practical levels and has come up with good recommendations to improve management of TNA, which will affect the effectiveness of $T \& D$ processes and programs in AGED; all were presented in the final chapter of this dissertation.

\footnotetext{
${ }^{*}$ Corresponding author.
}

How to cite this paper: Altarawneh, I.I. and Aseery, A.I.A. (2016) Training Needs Assessment at Assir General Educational Directorate, Saudi Arabia. American Journal of Industrial and Business Management, 6, 188-204. 


\section{Keywords}

\section{Training Needs, Training, Development, Human Resources, Abha}

\section{Introduction}

Much attention has been given within organizations to Human Resource Development (HRD) activities, particularly to Training and Development ( $\mathrm{T} \& \mathrm{D}$ ), which aims to prepare and provide people with the required new skills, knowledge, methods and work strategies to carry out their current and future responsibilities. Management authors and scholars, such as [1]-[4], argue that in order for organizations to deal with and manage the continuous environmental challenges and changes and to further the goals of economic progress, they must understand the vital role that training, learning and development will play in ensuring their survival. That implies that each organization in today's changing world must recognize the importance of developing employees' knowledge, skills and abilities and have flexible, qualified, and trained workforce.

Moreover, many authors and commentators argue that in order for $\mathrm{T} \& \mathrm{D}$ to be an influential activity in terms of helping the organization to gain superior performance and achieve its strategies or objectives, T \& D activities should be integrated and derived from the overall organization strategy, policies and plans [2] [3] [5]-[8]. It also should be supported by top management and line managers, and should have clear formal strategies, plan and policies; all T \& D stages should be managed in professional systematic manners including Training Needs Assessment (TNA) stage.

In Arab organizations context, training is supposed to be the most crucial factor facing development in the third world [4] [9]. But unfortunately, T \& D in many Arab organizations is not recognized as an important organizational function which contributes to the organization's success. Instead, it is viewed as a vacation activity or leisure time which is given to some people. In Arab countries, T \& D has been influenced by Arab executives who work within a social structure where family and friendship play important roles in their management style and leadership. So, there is a conflict between what should be done relating to the T \& D decision and what is constrained by the organizational culture [10]-[14]. [15] found that Arab countries perform some aspects of the management of $\mathrm{T} \& \mathrm{D}$ in a way consistent with modern management theories and practices, but still they are highly deficient in the TNA and program evaluation phases.

Moreover, [16] found that assessing T \& D needs by performance reports or by bosses point views does not always reflect the true situations and needs of employees because they may be unclear, may not have been prepared recently, or may be subject to family, kinship, tribalism and friendship ties. In addition, western T \& D managerial practices, programs and techniques have been used and applied in these organizations without any considerations being given to whether they work in the context of the Arab socio-cultural environment. As a result, the application of these practices does not usually work, so it remains as a waste of time, resource and effort [9].

The literature review shows that $\mathrm{T} \& \mathrm{D}$ in organizations is still considered to be a reactive activity and sometimes an isolated, stand-alone process, planned interventions designed to react to the current organizational needs [9]-[14]. Many managerial scholars such as [9] [14] [17]-[19] argue that, although T \& D plays a critical role in organizational performance it may be considered as an unnecessary, underused and unrecognized function. Some organizations find that T \& D does not contribute to employees' commitment; sometimes T \& D is considered as a costly function which consumes a lot of money, efforts and time. It is considered in some organizations as a waste of money and time. Some other organizations do not believe in the importance of T \& D in improving the overall organizational performance and success due to the fact that $\mathrm{T} \& \mathrm{D}$ could not prove its effectiveness in terms of calculating ROI, and for the difficulties to measure and evaluate the impacts of T \& D in measurable or financial terms. Moreover, many researchers argue that the unsystematic management for T \& D stages such as planning, TNA, and evaluation may hinder the effectiveness of T \& D in organization.

Therefore, this study is expected to extend T \& D literature; it aims to add more and fills the gap in the literature of T \& D management in Arab countries. It is also expected to contribute in enhancing the effectiveness of $\mathrm{T} \& \mathrm{D}$ management by being an exploratory study concerned specifically with exploring the management of TNA process in Assir General Educational Directorate (AGED) in Abha. Specifically, this study aims to shed 
the light on one of the most important T \& D stages, in particular on the management of TNA process, through exploring the methods and tools used for determining training needs in AGED in Abha, and determine whether these methods are systematic or not. Also this study is concerned with exploring T \& D problems and obstacles. Importantly this study aims to provide some practical suggestions and recommendations to improve TNA process in AGED in Abha.

\section{Literature Review and Related Studies}

\subsection{Human Resources Development (HRD)}

HRD is defined as "a series of organized activities conducted within a specified time and designed to produce behavioral changes" ([8], p. 57). [3] argues that there are many attempts to define HRD, these attempts have been varied, reflecting the diverse academic and socio-political backgrounds of HRD scholars. The problem of the definition is particularly apparent since each authority on the subject appears to adopt a different stance [8]. Thus, HRD could be defined in many different contexts and contains wide ranges of different and complex activities, such as education, development and training. That causes a confusion and makes it difficult to "put it into a box" [20]. However, HRD is still viewed as an important function of HRM concerned with planning and managing people's learning. HRD aims to make learning more efficient and effective; learning is either education for life or training for work.

However, many authors provide many definitions for HRD. For example, [21] also describes HRD as a function which includes T \& D, career planning and performance appraisal and focuses on the acquisition of the necessary skills, knowledge and attitudes essential to facilitate the achievement of employees' career goals and corporate objectives. Therefore, it contains some important activities: training (a short-term acquisition of the skills and attitudes necessary to make people more effective when undertaking their current jobs); education, (intermediate changes in individuals' capabilities; and development, long-term improvements in the individuals' work).

A current preoccupation with the practices of HRD literature is with the definition and justification of a new role for HRD as a set of organizational activities designed to facilitate learning organizations. In this regard, [20] state that HRD is more frequently understood and considered as important interventions to facilitate and support training processes in organizations and contribute to organizational learning processes. Specific dimensions of this superior role include: enhancing the learning capacities of employees; developing the impression that learning is a shared responsibility; viewing learning processes as a part of everyday working; fostering conditions which facilitate organizational learning. Moreover, HRD is concerned with identifying and enhancing the core competencies required at each level to meet the environmental challenges and changes. It is also concerned with selecting the best delivery systems designed to enhance human resource competencies and organizations' and individuals' growth. HRD focuses on the management and delivery of training activities within the organizations. So, it consists of a set of generic activities associated with learning and training.

\subsection{Training and Development (T \& D)}

$\mathrm{T} \& \mathrm{D}$ is the most important activity or subsystem of HRD, it concerns with increasing, improving, enhancing and modifying employees' skills, abilities, capabilities and knowledge, so that they will be able to conduct their current and future jobs effectively, thereby increasing individuals' and organizations' growth and performance. The Manpower Services Commission (1981) in [14] defines training as "a planned process to modify attitude, knowledge and skills through learning experience to achieve effective performance in an activity or range of activities". It defines development as "the growth of realization of a person's ability, through conscious or unconscious learning. Development programs usually include elements of a planned study and experience and are frequently supported by a coaching or counseling facility". On the other hand, it defines education as "activities, which aim at developing the knowledge, skills and understanding required in all aspects of life, rather than knowledge and skills relating to only a limited field of activity. The purpose of education is to provide the conditions essential to the young people and adults to develop an understanding of traditions and ideas influencing the society in which, they live and to enable them to make a contribution to it". Education often takes place in classrooms and involves transferring knowledge through using formal methods, such as lectures and directed discussion. Participants gain new information but the acquisition of new skills and knowledge designed to en- 
hance profitability is not the intended outcome.

Therefore, the distinction between Training and Development is that training is concerned with enhancing and improving individuals' skills, knowledge, behavior and attitudes in order to be able to conduct their current job effectively, thus, improving individuals' on-the-job performance while, development activity concerned with developing individuals' skills, knowledge, attitudes and behaviors in order to be able to conduct their future job effectively. Nevertheless, although training is concerned with current or present jobs its benefits may continue throughout the employees' entire career and helps in preparing them for future promotion.

While the main distinction between training and education is that training is a kind of learning by doing, while education is learning without doing. In education people learn something, but it is not necessary that they apply or transfer what they learn, while, in training, people do/will or are supposed to apply or transfer what they learn into their workplace, not just keep it in their mind. Practically, there is a difference between when you know about something and when you are able or willing to do that thing [4].

\subsection{Training Needs Assessment (TNA)}

TNA is defined as an analysis, or investigation that undertaken to determine the nature of performance problems in order to establish the underlying causes and the way in training can address this. TNA is considered the critical stage by which T \& D needs are identified. This stage determines the whole direction and purpose of T \& D processes. [22] describes TNA as the phase of the instructional process that provides the information necessary to design the entire T \& D program. So a training gap is defined as the difference between the required standard of the job and incumbent's performance. Therefore, TNA can be considered to be the starting point in any T \& $\mathrm{D}$ activity. TNA is not a routine function and it should be conducted carefully and in a diagnostic manner the assessment begins with a "need" which can be identified in several ways but is generally described as a gap between what is currently in place and what is needed, now and in the future.

So it can be said that TNA is an ongoing process of gathering data to determine what training needs exist so that training can be developed to help the organization accomplish its objectives [8]. More simply, it is the "process of collecting information about an expressed or implied organizational need that could be met by conducting training" [23]. Essentially, a TNA is a process through which a trainer collects and analyzes information, then creates a training plan. This process determines the need for the training; identifying training needs; and examines the type and scope of resources needed to support training [21]. According to [24], training needs should not only be assessed at the first step, since the T \& D process is affected by a variety of environmental factors that could affect the whole T \& D outcomes and results. Thus, the T \& D approach should be flexible enough to reassess T \& D needs during all the stages in order to take any urgent T \& D needs into account.

TNA aims to determine the gap between the actual level of performance and the desired one. It involves identification of T \& D needs through making a series of assessments inside and outside the organization and then establishes T \& D objectives to meet these needs. [23] contend that individual and group needs, which are supposed to fit with the entire organization's needs and objectives, are very important dimensions in determining T \& D needs. So, individual, group and organizational needs should be interrelated and interconnected. Also, training needs should fit the organization's culture as well as the organization's corporate strategy; thus, T \& D will help to achieve the organization's corporate objectives. [25] has promoted a "Deficiency Model Approach" as one of the most important approaches when identifying training needs as the difference between what people know and can do and what they should know and be able to do. This model identifies training needs based on the available skills and knowledge and the desired skills and knowledge. [26] also explains that one conducts a (TNA) to seek information about first optimal performance or knowledge; second the actual or current performance or knowledge; and thirdly feelings of trainees and other stakeholders; fourth, causes of identified problems; and solutions.

Conducting an effective assessment ensures that training is the appropriate solution to a performance deficiency. For example, training is not the solution to problems caused by poor system design, inadequate resources or understaffing [25]. In some cases, increasing an employee's knowledge and skills may not resolve the problem or deficiency. In such cases, implementing training as the solution may waste valuable resources and time.

To determine T \& D needs and objectives there are three dimensions for the assessment process: 1) organisational needs, 2) task needs and 3) individual needs [21] [22] [25]. Figure 1 explains the most important sources of information under each dimension. 


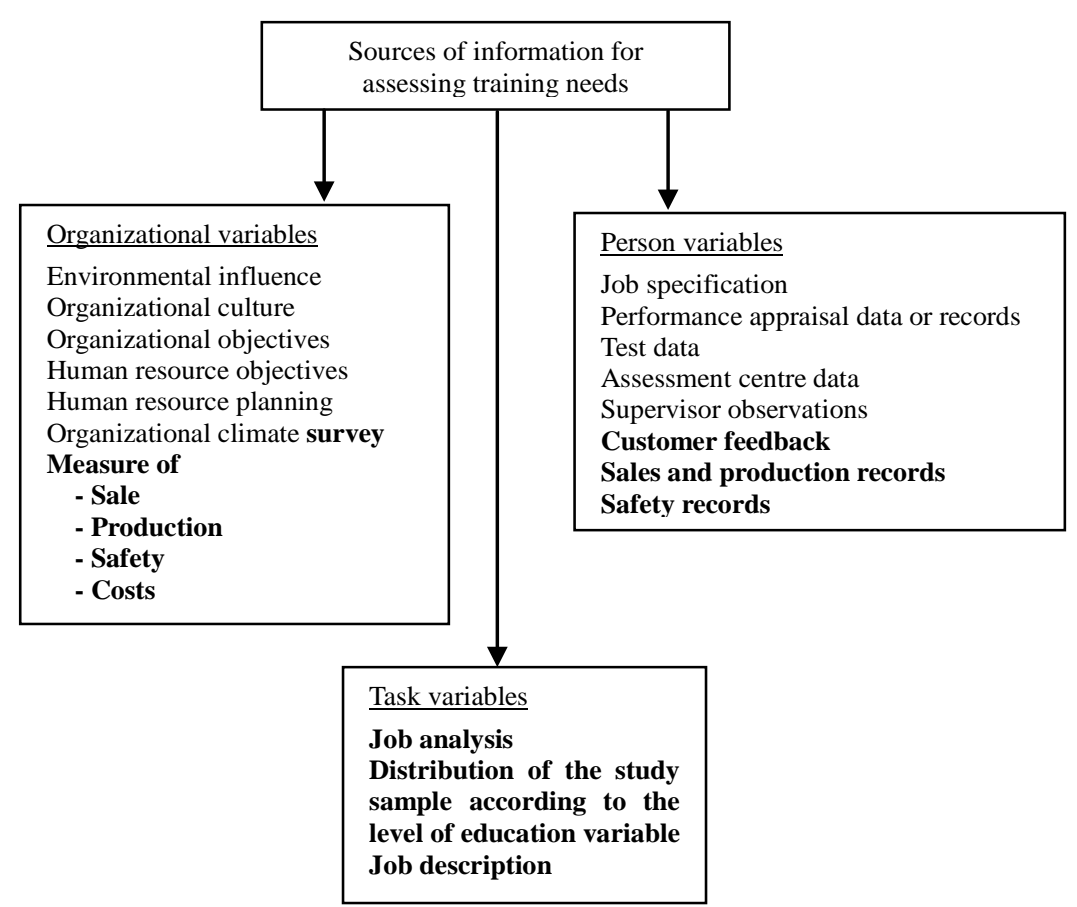

Figure 1. Training needs analysis sources ([21], p. 327) in [14].

\section{- Organization analysis}

According to [8] [21] [27] [28] looks at the organization's needs as a whole. It aims to determine where T \& $\mathrm{D}$ activities are required in the organization and where they will be successful; also to find out how $\mathrm{T} \& \mathrm{D}$ programs can contribute to achieve the organization's goals and objectives. Organizational needs analysis also helps to identify the allocated resources for the T \& D program and identify areas of the actual or potential weaknesses that could be corrected by training.

\section{- Job analysis}

[29] in ([30], p. 187), defines job analysis as "a process of identifying the purpose of a job and its component parts, and specifying what must be learned in order for there to be effective work performance". So job analysis is about collecting, recording, tabulating and analyzing duties and tasks, identifying employees' competencies necessary to perform their jobs, identifying job performance standards, knowledge, skills and abilities essential to perform these tasks. This analysis answer the question of what job needs T \& D and where. Many resources could be used to do this analysis shown in Figure 1.

\section{- Individual need analysis}

Finally, individual needs analysis according to [21] [31] examines employees' performance and compares it with the established standards, in order to determine the training needs for each employee. Thus, it focuses on how well employees perform their jobs and what skills, abilities and knowledge they use to conduct those jobs. Basically, person analysis answers the questions of which people need training and what kinds of training they need. In order to answer such questions we need to find what specific skills and knowledge are to be developed if the employee is to perform his/her job well.

\subsection{Training and Development in Saudi Arabia}

Saudi Arabia is emerging as a modern nation in the world economy so it has to maintain decent HR policies for the benefit of its companies as well as for the benefit of employees. Generally HR Policies in Saudi Arabia are oriented for the betterment of working conditions. Each company has a separate HR division and the HR Policies are set up to boost up the interest of the employees. Special attention is given to expatriates as they step in a different culture which is previously unknown to them. Some of the salient points in HR policies in Saudi Arabia are: favorable pay scale, $100 \%$ tax free salary; free accommodation, transportation, airfare; leave facilities; working hours as per international standards; bonus for overtime; bonus for religious purposes; and security to 
the work.

Interest has emerged the Ministry of education training through the establishment of educational training of management (1394/1395) and was tied at the time with the General management of teacher training programs, in: (1401-1981) annexed to General Directorate of educational guidance and training in the month of Jumada Al-Thani, Minister of education resolution No. 1674/48, on: 10/6/1401-1981, then became General Manager of educational training and scholarship in (1420-1990)

Training objectives and trends in Saudi Arabia are the following:

1) to prepare the employee for job vacancy Centre or busy with overseas contracting needs filled to the preparation or special training;

2) to raise the performance level of staff or improve the administrative environment in government bodies through methods of work;

3) to create a new work approach or the use of modern machines;

4) to retrain or set up to be directed to some new contacts as a result of the conditions of employment or staff.

Moreover, technical and administrative training is an essential part of education in the Kingdom. There are numerous public and private training institutions that produce thousands of graduates in the technical and mechanical sciences, health care, agriculture, teaching and other areas every year. These institutions include the Royal Technical Institute in Riyadh, the Hofuf Technical Training School, and centers in Jeddah, Madinah, Abha, Taif, Unayzah, Dammam and other cities. They train thousands of young Saudis in a variety of fields, including machine tooling, metalworking, electro mechanics, auto mechanics, electronics and maintenance of industrial machinery. Another important institution is the Institute for Public Administration in Riyadh. Established in 1961 as a semi-independent public agency, the institute offers courses in administration, law, accounting, computer science, maintenance, personnel management, secretarial skills and management planning. Today, the institute has branches in Dammam and Jeddah, as well as a special branch for women in Riyadh.

Most of the Kingdom's vocational training centers and higher institutes of technical education are operated by the General Organization for Technical Education and Vocational Training (GOTEVOT), along with the Ministry of Labor and the Ministry of Social Affairs. The Ministry of Education runs vocational secondary schools, and several other government agencies operate institutes or training centers in their particular specialties. There are also a number of private training centers meeting the needs of the marketplace.

\subsection{Previous Related Studies}

There are many previous related studies the researchers use to conduct the current study; these studies are best presented in Table 1.

\section{Methodology and Study Design}

This study can be considered as an exploratory study aims to explore TNA practices and management at AGED in Abha. As many other business and management researches it adopts the quantitative research approach by using the survey research strategy. The data collected by the survey strategy is unlikely to be as wide-ranging as those collected by other research strategies. The questionnaire is a data collection technique that belongs to the survey strategy which is used also in this research.

\subsection{Population and Sampling Technique}

The decision was to target all the female supervisors at AGED as they are responsible for selecting trainees from different schools and departments in Abha, and they suppose to be responsible for running $\mathrm{T} \& \mathrm{D}$ management in AGED. There are 114 female supervisors work at AGED the place where the first researcher works. However, just 100 persons accepted to participate, while the rest did not participate for different reasons: some were not satisfied (frustrated) with T \& D in AGED. So they said that they had not got the motivation to participate or to talk about T \& D at all. Some other participants apologized as they were busy during the data collection time.

\subsection{Data Collection Method}

In this research the exploration of TNA current practices and management is based on female supervisors worked 
Table 1. But after it the previous studies.

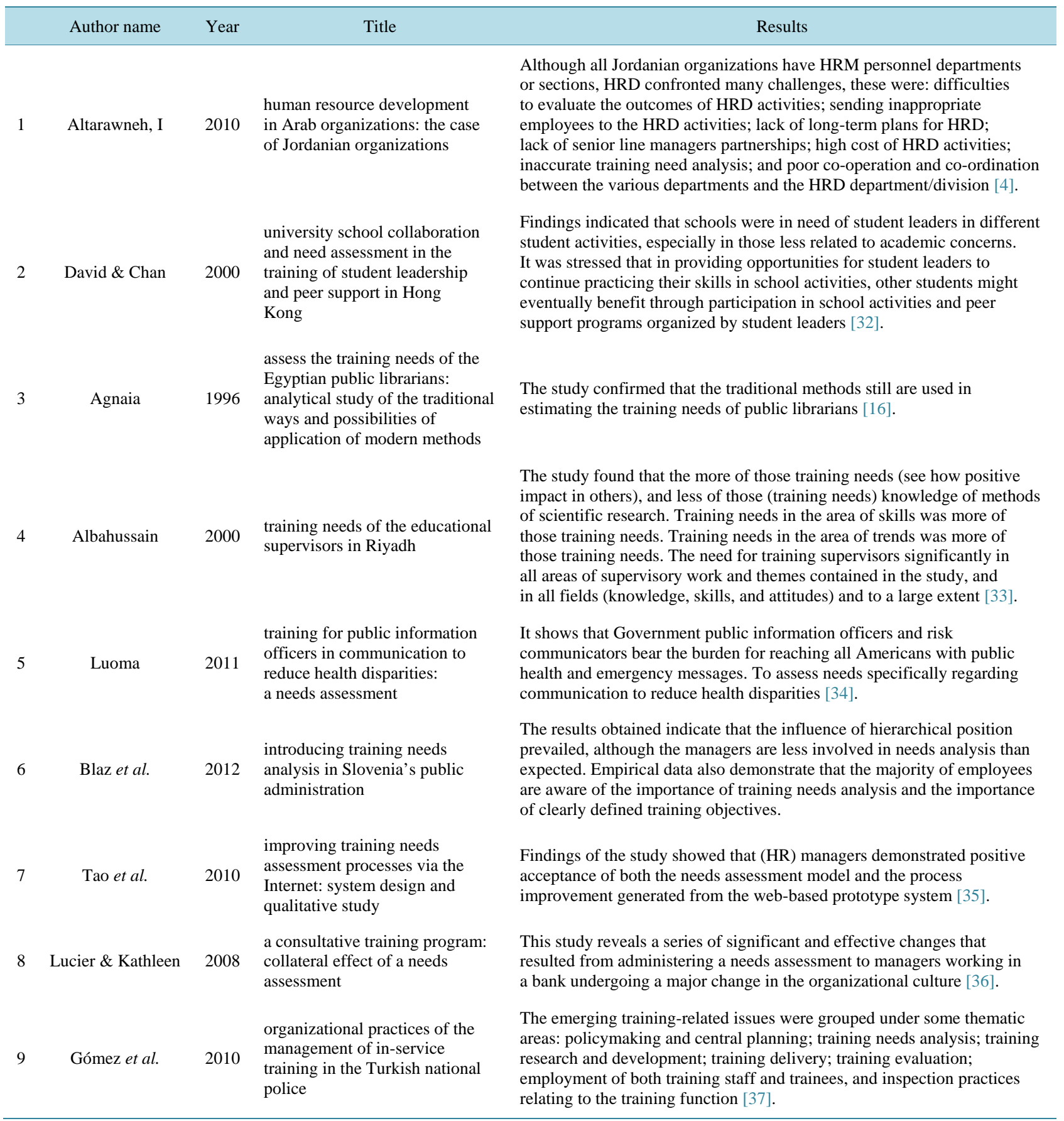

at AGED viewpoints and was carried out by using the survey self-administrated questionnaire (delivered and collected by the researchers). The questions included in the questionnaire were based on searching the previous studies in managing T \& D and HRM. It was decided that using previous studies' questionnaires (with, of course, making some necessary modifications to the original content to be applicable to the current study context) would ensure the study's validity and reliability and compare the result of this study with other related studies. Therefore, the study questionnaire was derived from different studies: [4] [33] [38]-[40].

The questionnaire contains different types of questions were organized as sections. The first section is about TNA process, it asks specifically: whether AGED conduct formal T \& D need assessment or not; what are the 
used TNA methods; how often they conduct TNA, what indictors are used to assess training needs and when T \& D is provided. The second section was assessing T \& D delivery methods. It involved data ranging from T \& $\mathrm{D}$ forms, the type of assistance provided by external providers and $\mathrm{T} \& \mathrm{D}$ methods and techniques and the organizational structure for T \& D section. The third section included a question about T \& D current challenges and problems. The final section included questions seek general information about the participants (job titles; management level, work experiences; education; ages and gender).

It is important to mention that three types of Likert scale were used throughout the questionnaire. The first one was (1) Never, (2) Rarely, (3) Sometimes, (4) Mostly, (5) Always. The second Likert scale was (1) To a very small extent, (2) To a small extent, (3) To a considerable extent, (4) To a great extent, (5) To a very great extent. The third Likert scale was (1) Strongly disagree, (2) Disagree, (3) Not sure, (4) Agree, (5) Strongly agree.

Moreover, important to mention also, that the questionnaire was translated to the participants' language (the Arabic) in order for them to understand it easily. Therefore, the questionnaire has been piloted many times and typed in two languages (Arabic and English). In total 100 questionnaires were distributed and 80 were retuned, however, 10 questionnaires were not useable (missed data). The data were collected within one week. Validity and reliability tests were conducted their results suggested that the questionnaire questions and variables were valid and reliable.

\section{Findings and Results}

\subsection{Findings of the Study Sample Characteristics}

This section presents the statistical description of the study sample according to their characteristics (gender, age, job title, job position, and work experiences in general, work experiences in T \& D and their educational level). Table 2 represents the results.

As it shown in Table 2, all the participants were female, 55.7\% of them were at age between 31 and 40. Most of the study participants (45.7\%) occupy jobs in the middle management, however, $25.7 \%$ occupy supervisory and technical jobs and $24.7 \%$ occupy jobs in high management. $62.9 \%$ of the participants had 15 year or more work experiences, interestingly 20 participants had 20 year or more. However, $47.1 \%$ had no work experiences in T \& D while $24 \%$ declared that they had more than 10 year work experiences in T \& D. $85.7 \%$ of the participants have university degree.

\subsection{Findings Related to TNA Process and Management}

\subsubsection{Do You Conduct Formal TNA in Your Organization?}

Participants were asked whether AGED conduct TNA when they train employees or not. Their answers were as follow: $42.9 \%$ of the participants indicated that they "never" identify the training needs; $17.1 \%$ declared that they "rarely" identify the training needs; $27.1 \%$ of the participants they "sometimes" identify the training needs. While, just $4.3 \%$ of the participants "frequently" identify the training needs of teachers and principals. $8.6 \%$ of the participants indicated they "always" identify the training needs of teachers and principals.

\subsubsection{Methods of Identifying the Training Needs}

The responses of the study participants regarding to methods of identifying the training needs were as follows in Table 3.

The results appear in Table 3 show that according to the participants responses to this questions: employees reports, functional description for employees; and direct observation and monitoring were in the first, second and third ranks as methods of identifying training needs. While, group meetings with trainees and questionnaires were in the sixth and seventh ranks.

\subsubsection{How Often Do the AGED Identify the Training Needs of Employees?}

$5.7 \%$ of the participants declared that the AGED identify training needs every six months. $44.3 \%$ of the participants said that the training needs are assessed every year (on a yearly base), 37.1\% believed that the AGED identify training needs within a period ranges from 2 to 3 years. 8.6\% of the participants declared that training needs within a period ranges from 4 to 5 years, $4.3 \%$ of the participants thought that the AGED assess training needs every 5 years or more. This proves that the majority of the participants believe that the AGED identify training need every year. 
Table 2. Sample characteristics results.

\begin{tabular}{|c|c|c|}
\hline Variables & Frequency & Percentage \\
\hline \multicolumn{3}{|l|}{ Gender } \\
\hline Male & 0.0 & $0.0 \%$ \\
\hline Female & 70 & $100.0 \%$ \\
\hline Total & 70 & $100 \%$ \\
\hline \multicolumn{3}{|l|}{ Age } \\
\hline From 20 to 30 years old & 7 & $10.0 \%$ \\
\hline From 31 to 40 years old & 39 & $55.7 \%$ \\
\hline From 41 to 50 years old & 19 & $27.1 \%$ \\
\hline Older than 50 years old & 5 & $7.1 \%$ \\
\hline Total & 70 & $100.0 \%$ \\
\hline \multicolumn{3}{|l|}{ Job position } \\
\hline High management & 17 & $24.3 \%$ \\
\hline Middle management & 32 & $45.7 \%$ \\
\hline Low management & 1 & $1.4 \%$ \\
\hline Supervisory and technical jobs & 18 & $25.7 \%$ \\
\hline Other & 2 & $2.9 \%$ \\
\hline Total & 70 & $100.0 \%$ \\
\hline \multicolumn{3}{|l|}{ Years of experience in the practical life } \\
\hline From 5 to 10 years & 15 & $21.4 \%$ \\
\hline From 10 to 15 years & 11 & $15.7 \%$ \\
\hline From 15 to 20 years & 20 & $28.6 \%$ \\
\hline More than 20 years & 24 & $34.3 \%$ \\
\hline Total & 70 & $100.0 \%$ \\
\hline \multicolumn{3}{|l|}{ Years of experience in $T$ \& $D$} \\
\hline None & 33 & $47.1 \%$ \\
\hline From 1 to 3 years & 7 & $10.0 \%$ \\
\hline From 3 to 5 years & 11 & $15.7 \%$ \\
\hline From 5 to 10 years & 17 & $24.3 \%$ \\
\hline More than 10 years & 2 & $2.9 \%$ \\
\hline Total & 70 & $100.0 \%$ \\
\hline \multicolumn{3}{|l|}{ Educational level } \\
\hline Matriculation degree & 5 & $7.1 \%$ \\
\hline Diploma form a community college & 3 & $4.3 \%$ \\
\hline University degree & 60 & $85.7 \%$ \\
\hline Master degree & 1 & $1.4 \%$ \\
\hline Doctorate degree or its equivalents & 1 & $1.4 \%$ \\
\hline Total & 70 & $100.0 \%$ \\
\hline
\end{tabular}




\subsubsection{Indicators of Identifying the Training Needs}

Regarding to the findings related to indicators of identifying training needs, Table 4 represents these results.

As it can be shown in Table 4, "Moving of employees from one department to another one" comes in the first rank with a mean reaches 3.34. "Poor quality of services/teaching" comes in the second rank with a mean reaches 3.33. The ninth phrase "Low morale of workers" comes in the third rank with a mean reaches 3.26. While, "Lack or poor skills of individuals" comes in the fifth rank with a mean reaches 3.20; "Low performance of the organization" comes in the sixth rank with a mean reaches 3.20 and "Higher levels of absenteeism" comes in the tenth rank with a mean reaches 2.97 .

\subsection{When Are Employees Trained?}

Table 5 represents the results related to when employees are trained in AGED according to the participants.

Table 3. Frequencies, means, percentages of the responses of the study sample regarding methods of identifying the training needs.

\begin{tabular}{|c|c|c|c|c|c|c|c|c|c|c|c|c|c|}
\hline \multirow{3}{*}{ Phrases } & \multicolumn{10}{|c|}{ Response } & \multirow{3}{*}{ Mean } & \multirow{3}{*}{ S.D } & \multirow{3}{*}{ Rank } \\
\hline & \multicolumn{2}{|c|}{ Never } & \multicolumn{2}{|c|}{ Rarely } & \multicolumn{2}{|c|}{ Sometimes } & \multicolumn{2}{|c|}{ Frequently } & \multicolumn{2}{|c|}{ Always } & & & \\
\hline & Freq & $\%$ & freq & $\%$ & Freq & $\%$ & Freq & $\%$ & freq & $\%$ & & & \\
\hline 1. Questionnaires. & 26 & 37.1 & 14 & 20.0 & 17 & 24.3 & 11 & 15.7 & 2 & 2.9 & 2.27 & 1.20 & Seventh \\
\hline 2. Interviews with employees. & 19 & 27.1 & 10 & 14.3 & 21 & 30.0 & 11 & 15.7 & 9 & 12.9 & 2.73 & 1.36 & Fourth \\
\hline $\begin{array}{l}\text { 3. Group meetings with principals and } \\
\text { supervisors. }\end{array}$ & 18 & 25.7 & 10 & 14.3 & 28 & 40.0 & 7 & 10.0 & 7 & 10.0 & 2.64 & 1.25 & Sixth \\
\hline 4. Direct observation and monitoring. & 12 & 17.1 & 12 & 17.1 & 26 & 37.1 & 15 & 21.4 & 5 & 7.1 & 2.84 & 1.16 & Third \\
\hline 5. A special committee for training. & 14 & 20.0 & 12 & 17.1 & 32 & 45.7 & 3 & 4.3 & 9 & 12.9 & 2.73 & 1.21 & Fifth \\
\hline 6. Reports of employees' efficiency. & 12 & 17.1 & 10 & 14.3 & 32 & 45.7 & 8 & 11.4 & 8 & 11.4 & 2.86 & 1.18 & First \\
\hline $\begin{array}{l}\text { 7. Functional description for individuals } \\
\text { and employees. }\end{array}$ & 12 & 17.1 & 9 & 12.9 & 31 & 44.3 & 13 & 18.6 & 5 & 7.1 & 2.86 & 1.13 & Second \\
\hline
\end{tabular}

Table 4. Frequencies, means, percentages of the responses of the study sample regarding to indicators of identifying the training needs.

\begin{tabular}{|c|c|c|c|c|c|c|c|c|c|c|c|c|c|}
\hline \multirow{3}{*}{ Phrases } & \multicolumn{10}{|c|}{ Response } & \multirow{3}{*}{ Mean } & \multirow{3}{*}{ S.D } & \multirow{3}{*}{ Rank } \\
\hline & \multicolumn{2}{|c|}{ Never } & \multicolumn{2}{|c|}{ Rarely } & \multicolumn{2}{|c|}{ Sometimes } & \multicolumn{2}{|c|}{ Frequently } & \multicolumn{2}{|c|}{ Always } & & & \\
\hline & Freq & $\%$ & Freq & $\%$ & Freq & $\%$ & Freq & $\%$ & Freq & $\%$ & & & \\
\hline $\begin{array}{l}\text { 1. Insufficient or lack of knowledge } \\
\text { among individuals. }\end{array}$ & 6 & 8.6 & 9 & 12.9 & 35 & 50.0 & 7 & 10.0 & 13 & 18.6 & 3.17 & 1.14 & Seventh \\
\hline 2. Lack or poor skills of individuals. & 3 & 4.3 & 14 & 20.0 & 30 & 42.9 & 12 & 17.1 & 11 & 15.7 & 3.20 & 1.07 & Fifth \\
\hline 3. Low performance of the organization. & 7 & 10.0 & 5 & 7.1 & 33 & 47.1 & 17 & 24.3 & 8 & 11.4 & 3.20 & 1.07 & Sixth \\
\hline 4. Providing new working strategies. & 5 & 7.1 & 14 & 20.0 & 29 & 41.4 & 13 & 18.6 & 9 & 12.9 & 3.10 & 1.09 & Eighth \\
\hline $\begin{array}{l}\text { 5. Dissatisfaction of students or } \\
\text { the increasing complaints. }\end{array}$ & 8 & 11.4 & 7 & 10.0 & 25 & 35.7 & 19 & 27.1 & 11 & 15.7 & 3.26 & 1.19 & Fourth \\
\hline 6. Poor quality of services. & 6 & 8.6 & 5 & 7.1 & 30 & 42.9 & 18 & 25.7 & 11 & 15.7 & 3.33 & 1.10 & Second \\
\hline 7. Higher levels of job turnover. & 8 & 11.4 & 7 & 10.0 & 28 & 40.0 & 24 & 34.3 & 3 & 4.3 & 3.10 & 1.04 & Ninth \\
\hline $\begin{array}{l}\text { 8. Moving of employees from one } \\
\text { department to another one. }\end{array}$ & 9 & 12.9 & 4 & 5.7 & 21 & 30.0 & 26 & 37.1 & 10 & 14.3 & 3.34 & 1.19 & First \\
\hline 9. Low morale of workers. & 7 & 10.0 & 14 & 20.0 & 15 & 21.4 & 22 & 31.4 & 12 & 17.1 & 3.26 & 1.25 & Third \\
\hline 10. Higher levels of absenteeism. & 13 & 18.6 & 12 & 17.1 & 20 & 28.6 & 14 & 20.0 & 11 & 15.7 & 2.97 & 1.33 & Tenth \\
\hline
\end{tabular}


It is clear from Table 5 that the fifth phrase "When requested from the department in which the employee works" comes in the first rank with a mean reaches 3.07. The second phrase "When or when technology aspects are employed or when new method of work are employed" comes in the second rank with a mean reaches 3.03. The fourth phrase "When employees are upgraded to occupy vacancies" comes in the third rank with a mean reaches 2.97. While, the third phrase "While evaluating the performance of employees" comes in the sixth rank with a mean reaches 2.69 .

\subsection{Methods Used in Internal Training}

Table 6 includes frequencies, means, and standard deviations to the responses of the study sample regarding to training strategies and methods. According to Table 6, "Lectures" comes in the first rank with a mean reaches 3.80. "Guidance and supervision" comes in the second rank with a mean reaches 3.53, "Group discussions"

Table 5. Frequencies, means, percentages of the responses of the study sample related to when are employees trained?

\begin{tabular}{|c|c|c|c|c|c|c|c|c|c|c|c|c|c|}
\hline \multirow{3}{*}{ Phrases } & \multicolumn{10}{|c|}{ Response } & \multirow{3}{*}{ Mean } & \multirow{3}{*}{ S.D } & \multirow{3}{*}{ Rank } \\
\hline & \multicolumn{2}{|c|}{ Never } & \multicolumn{2}{|c|}{ Rarely } & \multicolumn{2}{|c|}{ Sometimes } & \multicolumn{2}{|c|}{ Frequently } & \multicolumn{2}{|c|}{ Always } & & & \\
\hline & Freq & $\%$ & Freq & $\%$ & Freq & $\%$ & Freq & $\%$ & Freq & $\%$ & & & \\
\hline $\begin{array}{l}\text { 1. Only one time when appointment } \\
\text { takes place. }\end{array}$ & 15 & 21.4 & 12 & 17.1 & 22 & 31.4 & 7 & 10.0 & 14 & 20.0 & 2.90 & 1.40 & Fourth \\
\hline $\begin{array}{l}\text { 2. When or when technology aspects } \\
\text { are employed or when new methods } \\
\text { of work are employed. }\end{array}$ & 11 & 15.7 & 12 & 17.1 & 23 & 32.9 & 12 & 17.1 & 12 & 17.1 & 3.03 & 1.30 & Second \\
\hline $\begin{array}{l}\text { 3. While evaluating the performance } \\
\text { of employees. }\end{array}$ & 12 & 17.1 & 14 & 20.0 & 29 & 41.4 & 14 & 20.0 & 1 & 1.4 & 2.69 & 1.03 & Sixth \\
\hline $\begin{array}{l}\text { 4. When employees are upgraded to } \\
\text { occupy vacancies. }\end{array}$ & 9 & 12.9 & 12 & 17.1 & 28 & 40.0 & 14 & 20.0 & 7 & 10.0 & 2.97 & 1.14 & Third \\
\hline $\begin{array}{l}\text { 5. When requested from the department } \\
\text { in which the employee works. }\end{array}$ & 8 & 11.4 & 14 & 20.0 & 24 & 34.3 & 13 & 18.6 & 11 & 15.7 & 3.07 & 1.22 & First \\
\hline $\begin{array}{l}\text { 6. When the employee himself } \\
\text { asks for training. }\end{array}$ & 12 & 17.1 & 15 & 21.4 & 25 & 35.7 & 10 & 14.3 & 8 & 11.4 & 2.81 & 1.22 & Fifth \\
\hline
\end{tabular}

Table 6. Frequencies, means, percentages of the responses of the study sample related to strategies and methods used in internal training.

\begin{tabular}{|c|c|c|c|c|c|c|c|c|c|c|c|c|c|}
\hline \multirow{3}{*}{ Phrases } & \multicolumn{10}{|c|}{ Response } & \multirow{3}{*}{ Mean } & \multirow{3}{*}{ S.D } & \multirow{3}{*}{ Rank } \\
\hline & \multicolumn{2}{|c|}{ Never } & \multicolumn{2}{|c|}{ Rarely } & \multicolumn{2}{|c|}{ Sometimes } & \multicolumn{2}{|c|}{ Frequently } & \multicolumn{2}{|c|}{ always } & & & \\
\hline & Freq & $\%$ & Freq & $\%$ & Freq & $\%$ & freq & $\%$ & freq & $\%$ & & & \\
\hline 1. Lectures. & 9 & 12.9 & 2 & 2.9 & 12 & 17.1 & 18 & 25.7 & 29 & 41.4 & 3.80 & 1.36 & First \\
\hline 2. Seminars and conferences. & 16 & 22.9 & 10 & 14.3 & 22 & 31.4 & 11 & 15.7 & 11 & 15.7 & 2.87 & 1.36 & Seventh \\
\hline 3. Group discussions. & 5 & 7.1 & 4 & 5.7 & 29 & 41.4 & 18 & 25.7 & 14 & 20.0 & 3.46 & 1.10 & Third \\
\hline 4. Researches and individual studies. & 20 & 28.6 & 14 & 20.0 & 27 & 38.6 & 7 & 10.0 & 2 & 2.9 & 2.39 & 1.09 & Tenth \\
\hline 5. Role playing. & 14 & 20.0 & 14 & 20.0 & 28 & 40.0 & 7 & 10.0 & 7 & 10.0 & 2.70 & 1.20 & Ninth \\
\hline 6. Management games. & 27 & 38.6 & 9 & 12.9 & 28 & 40.0 & 6 & 8.6 & 0.0 & 0.0 & 2.19 & 1.05 & Twelfth \\
\hline 7. Practical show. & 12 & 17.1 & 6 & 8.6 & 21 & 30.0 & 16 & 22.9 & 15 & 21.4 & 3.23 & 1.35 & Fourth \\
\hline 8. Case studies. & 24 & 34.3 & 18 & 25.7 & 21 & 30.0 & 4 & 5.7 & 3 & 4.3 & 2.20 & 1.11 & Eleventh \\
\hline 9. Electronic computers. & 10 & 14.3 & 9 & 12.9 & 27 & 38.6 & 8 & 11.4 & 16 & 22.9 & 3.16 & 1.31 & Fifth \\
\hline 10. Video tapes. & 17 & 24.3 & 12 & 17.1 & 17 & 24.3 & 15 & 21.4 & 9 & 12.9 & 2.81 & 1.37 & Eighth \\
\hline 11. Guidance and supervision. & 3 & 4.3 & 4 & 5.7 & 34 & 48.6 & 11 & 15.7 & 18 & 25.7 & 3.53 & 1.07 & Second \\
\hline 12. Work turnover. & 11 & 15.7 & 14 & 20.0 & 23 & 32.9 & 10 & 14.3 & 12 & 17.1 & 2.97 & 1.30 & Sixth \\
\hline
\end{tabular}


comes in the third rank with a mean reaches 3.46 and "Practical show" comes in the fourth rank with a mean reaches 3.23. While, "Case studies" comes in the eleventh rank with a mean reaches 2.39 and also "management games" comes in the twelfth rank with a mean reaches 2.19.

\subsection{Factors That Hinder T \& D}

To review the results of the "Factors that hinder T \& D", Table 7 includes frequencies, means, and standard deviations to the responses of the study sample regarding factors that hinder T \& D. it shows that: "Lack of motivation to participate in training and development programs because of the lack of support from the external environment such as (family, friends, etc.)" comes in the first rank with a mean reaches 3.93. "Lack of time and budget to support the training process" comes in the second rank with a mean reaches 3.86. The existence of many shortcomings in the content of training programs and unsuitable methods and strategies used in training" comes in the third rank with a mean reaches 3.81 .

\section{Discussions}

The primary purpose for this study was to explore and the current practices and management of TNA in AGED at Abha city in Saudi Arabia and to explore factors that affecting T \& D effectiveness in the targeted organization. Based on the statistical results presented before the following findings can be drawn:

\subsection{Findings Related to the Participants Characteristics}

The first finding that all participants were female (women); no male members participated in the study. As mentioned before the researchers had no access to the male participants for cultural issues in addition to the time constrain. 58 participants their ages were between 31 - 50 years old and 39 of them were between 31 - 40 years old; this indicates for young workforce. Their job title was female supervisors in AGED. Most of them considered their jobs to be in the middle management level. 44 participants declared that their work experiences were 15 years or more. The majority of the participants (47.1\%) had no experience in the field of T \& D, this is very important finding indicates for lack of knowledge about T \& D management. However, they are well-educated as 60 participants hold university degrees.

\subsection{Findings Related to TNA Process and Management}

The review of T \& D literature suggests that a systematic approach to T \& D should begin with TNA. TNA is considered the critical stage by which T \& D needs are identified. In this regard, [41] argue that assessing training needs plays a very important role in identifying individuals who need to be trained, designing the program that relates to the needs of both individuals and the organization, allocating the required time, determining the program objectives and the required skills and determining the required resources for implementing the program. TNA should be based on analyzing organizational tasks or jobs and personal needs, not just one source of analysis. T \& D should be based on the organization, jobs and individuals' real needs.

In order to judge the effectiveness of TNA process in EGAD participants were asked different important questions regarding the regularity of conducting the TNA process, TNA methods or techniques, indicators to assess training needs and when employees received T \& D. It was found that in term of regulatory of TNA, in spite of the importance of identifying and assessing the training needs of individuals; the majority of the study participants $(42.9 \%)$ chose response "never" for identifying the training needs of teachers and principals and $17.1 \%$ of the participants choose "rarely" for identify the training needs of teachers and principals only $8.6 \%$ of the participants showed that they always identify the training needs of teachers and principals. These findings indicate that employees training needs in AGED are never or rarely assessed. This of course will affect the effectiveness and the impact of T \& D programs on their performance as people attend T \& D program which may do not need to attend.

Moreover, regarding to methods of identifying the training needs, the results indicate that the participants do not greatly depend on the previous presented methods when identifying the training needs as all the phrases mentioned above obtained lower degrees. This may be interpreted from the viewpoint that the management follows traditional methods in identifying the training needs and it does not take in its consideration the opinions of the study participants regarding the methods that can be used in determining their training needs. So when 
Table 7. Frequencies, means, percentages of the responses of the study sample related to factors that hinder (T \& D).

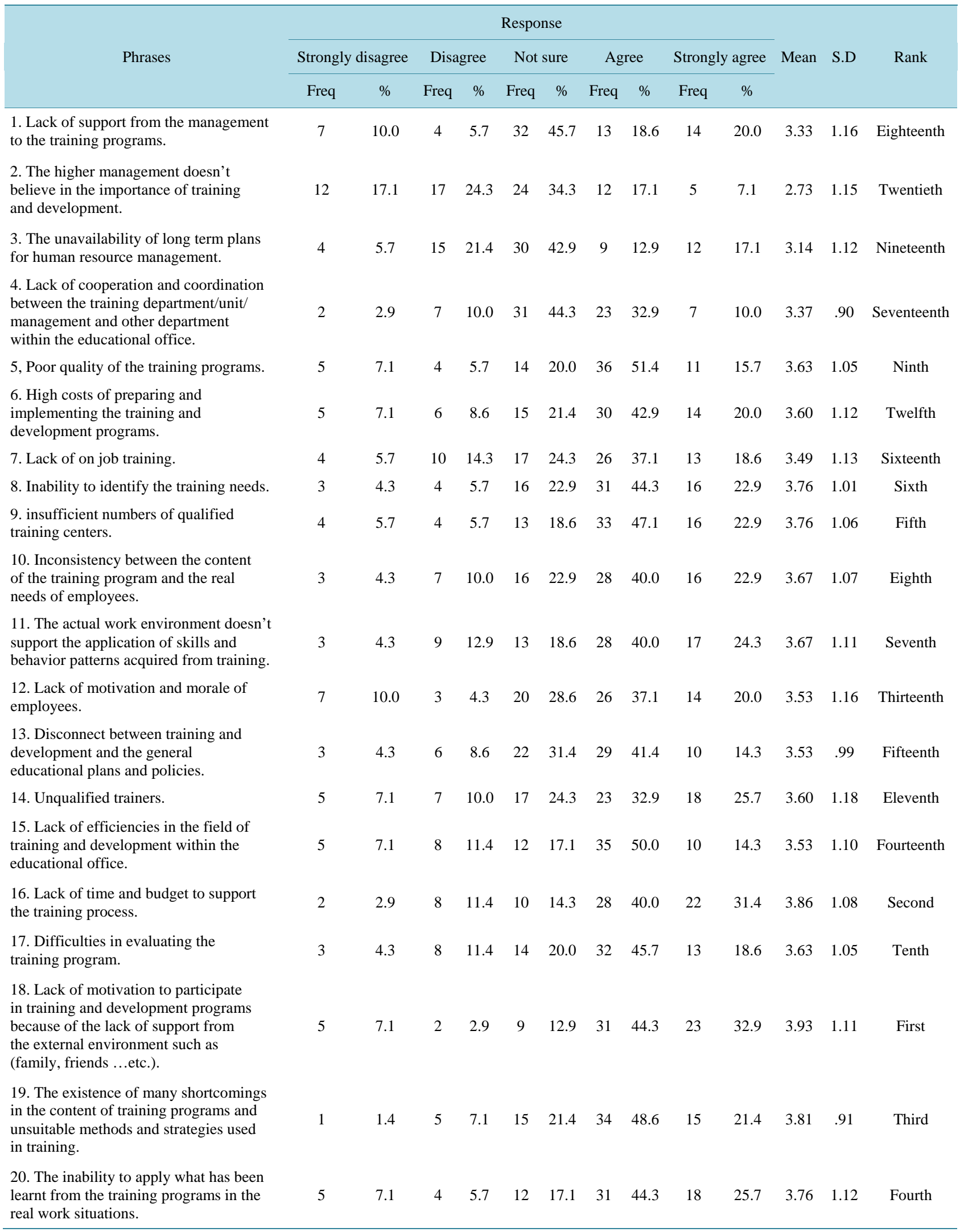


determining T \& D they depend on other methods for determining who should attend T \& D programs. The most important thing here is that employees' needs are not assessed based on individual or organisational or task needs rather they are nominated to attend $\mathrm{T} \& \mathrm{D}$ based on subjective reasons which could lead to the fact that you may attend $\mathrm{T} \& \mathrm{D}$ program and you do not really understand or need it at all.

[41] argue that a few organizations are committed to enhance employees' skills and competences. Other organizations conduct training to meet current job requirements. The AGED in Abha identifies the training needs of employees annually. Regarding the indicators of training needs, the participants stated that moving of employees from one department to another one, poor quality of services, low morale of workers, dissatisfaction of students or the increasing complaints and lack or poor skills of individuals are among the most important indicators of training needs. There are certain times in which employees need training when requested from the department in which the employee works or when technology aspects are employed or when new method of work are employed or when employees are upgraded to occupy vacancies. These findings seem to be consistent with those relating to Arab TNA practices reviewed. For instance, [12] found that there are no specific or systematic practices or procedures for determining training and educational needs. They also found that about $69 \%$ of private and joint-venture Kuwaiti organizations had no systematic practices for TNA. Also, many Arab researchers have argued that the lack of job description, clear performance appraisal and the approach used for assessing the development needs of employees are impressionistic and generalized, rather than systematic. Arab organizations rely on different sources to obtain the information required to determine training needs, mainly on supervisors and trainees themselves (self-assessment), but less on task or job requirements, description and manpower planning. In this context, also, [16] found that few employees are selected on the basis of greatest need; bureaucratic policies and patronage play more important roles.

Regarding to $\mathrm{T} \& \mathrm{D}$ methods and techniques the results show that $\mathrm{T} \& \mathrm{D}$ can be done using many methods and techniques, the most common methods identified by the participants and used in internal training are: lectures, guidance and supervision, group discussions, practical show and electronic computers. On the other hand, the most common methods used in external training are: lectures, seminars and conferences, guidance and supervision, group discussions, electronic computers and video tapes. By analysing the different methods used in internal and external training. It can be argued that that role playing, researches and individual studies and management games are uncommon methods in both internal and external training. Also it can be argued that the used T \& D methods in AGED are the most passive traditional methods that can be used mainly the lecture. In this context, [43] points out that there are four main methods which have often been used in the Jordanian organizations: on-the-job training; in-company training; external training within the local institutions; overseas training. This finding is also consistent with [39], who found that classroom training (off-the-job training) was the most important training approach in Kuwaiti organizations, representing $66 \%$ and $60 \%$ of the government and private organizations, respectively. However, [33] found that on-the-job training was the most frequently used approach of training, while, off-the-job training was sometimes resorted to but that in general, it was a rare event.

Regarding to T \& D main challenges in AGED it can be said that according to [44] and [45] effective T \& D programs require the dedicated support of top management. In this study participants identify some factors that hinder the effectiveness of $\mathrm{T} \& \mathrm{D}$ programs such as:

- Lack of motivation to participate in training and development programs because of the lack of support from the external environment such as (family, friends, etc.).

- Lack of time and budget to support the training processes.

- The existence of many shortcomings in the content of training programs and unsuitable methods and strategies used in training.

- The inability to apply what has been learnt from the training programs in the real work situations.

- Insufficient numbers of qualified training centers.

- And the inability to identify the training needs.

These are the most important factors hinder the effective implementation of T \& D in AGED, which lead to the poor performance of individuals within the educational system and the poor quality of the educational outcomes. These findings of the study agreed partially with Armstrong's viewpoint, [25] argues that T \& D will fail to obtain its objectives and affect organizational performance if it is based on a piecemeal basis and is used in isolation without the backing of top management. 


\section{Conclusions, Implications, and Future Research Directions}

Many significant conclusions can be made in this current study. First, in spite of the importance of identifying and assessing the training needs of individuals training needs have never been assessed or identified, and if they are assessed they will be assessed yearly. Second, participants do not greatly depend on the presented systematic TNA methods when identifying the training needs at all; the phrases mentioned above obtained lower degrees; this may be interpreted from the viewpoint that the management follows traditional methods in identifying the training needs. Third, TNA indicators in AGED in Abha are: moving of employees from one department to another one, poor quality of services, and low morale of workers; dissatisfaction of students or the increasing complaints and lack or poor skills of individuals are among the most important indicators of training needs. Fourth, T \& D methods and techniques are: lectures, guidance and supervision, group discussions, practical show and electronic computers. Fifth, T \& D main challenges and problems are: lack of motivation to participate in training and development programs because of the lack of support from the external environment such as (family, friends, etc.); lack of time and budget to support the training processes; the existence of many shortcomings in the content of training programs and unsuitable methods and strategies used in training; the inability to apply what has been learnt from the training programs in the real work situations; insufficient numbers of qualified training centers; and the inability to identify the training needs. Sixth, TNA techniques could be described as highly subjective because they depend mainly on what managers or supervisors think about their employees' training needs, rather than on what performance appraisal records show or what the employees' job descriptions show, in addition to observation and the managers' viewpoints.

The current study has many implications for HR, T \& D managers, trainees, trainers and other managerial practitioners. The findings of this study, which have revealed several important implications for $\mathrm{T} \& \mathrm{D}$ professionals, including all the issues related to T \& D activities at AGED in Abha, are presented throughout the study. It is important to stress that one of the main research questions and objectives was to explore and suggest what needs to be done in order to improve the T \& D situation in AGED. This study has provided useful guidelines in the form of the critical elements and factors that can enhance success in T \& D. It provides assessments for the effectiveness of the current practices relating to the TNA process which is considered as a very critical stage for effective T \& D programs in order to enhance the role of T \& D in the organizational development and success.

For scholars, the academic contributions of this research can represented as follows:

- This study can be described as an important exploratory study that includes important issues which need to be understood for managing effective and successful T \& D functions and programs in organizations. It includes T \& D and TNA current management and practices in AGED in Abha city.

- This study contributes to knowledge as being the first exploratory empirical study conducted in AGED in Abha city. So it raises and improves the understanding of T \& D current practices and management in Saudi Arabia and enriches and fills the gaps in the literature of T \& D in Arab countries.

- This study raises awareness of the importance of the T \& D function as an important strategic function, which could help organizations to achieve corporate strategies and gives a better understanding of how $\mathrm{T} \&$ D could be effectively approached and implemented.

- This study has explored many new ideas and facts which could be considered as directions for future work.

It must be said that like any other researches the current study has some special limitations; this study is limited to identify the training needs in AGED in Abha not in other cities within the Kingdom of Saudi Arabia. Also, the study is limited to those who are working in AGED in Abha for time constrain, and as a result it does not include principals or supervisors from other educational directorates.

As directions for future work and research, the researches recommend conducting similar studies to identify the training needs of teacher and principals in other regions within the Kingdom of Saudi Arabia, or conducting similar studies to identify the training needs of teachers and principals from their own viewpoints, and also conducting future studies to determine the effect of identifying the training needs on the performance of employees and on the effectiveness of the training program itself. A research sample studying T \& D practices within two or more sectors would provide more valuable information and provide the opportunity to compare between them.

\section{References}

[1] Mondy, W., Noe, M. and Premeaux, R. (1999) Human Resource Management. 7th Edition, Prentice-Hall International, London. 
[2] Garavan, N. (1991) Strategic Human Resource Development. Journal of European Industrial Training, 15, 17-30. http://dx.doi.org/10.1108/EUM0000000000219

[3] Nolan, C. (2002) Human Resource Development in the Irish Hotel Industry: The Case of the Small Firm. Journal of European Industrial Training, 26, 88-99. http://dx.doi.org/10.1108/03090590210421969

[4] Altarawneh, I. (2010) HRD in Jordanian Organizations. International Journal of Business, Management and Social Science, 1, 41-54.

[5] Garavan, N., Costine, P. and Heraty, N. (1995) The Emergence of Strategic Human Resource Development. Journal of European Industrial Training, 19, 4-10. http://dx.doi.org/10.1108/03090599510095816

[6] McCracken, M. and Wallace, M. (2000) Exploring Strategic Maturity in HRD-Rhetoric, Aspiration or Reality. Journal of European Industrial Training, 24, 425-467. http://dx.doi.org/10.1108/03090590010354344

[7] Berge, N., Davis, L. and Smith, D. (2003) The Increasing Scope of Training and Development Competency. An International Journal, 9, 43-61.

[8] Walton, J. (1999) Strategic Human Resource Development. Financial Times, London.

[9] Rowland, C., Hall, R. and Altarawneh, I. (2011) Is It Working? Managing Performance through Training and Development in Jordanian Banking. Proceeding Annual for the 25 the Annual British Academy Management, Aston University, Birmingham "Building and Sustaining High Performance Organisations in a Challenging Environment”, 13-15 September 2011, Paper ISBN Number 978-0-9549608-3-4.

[10] Bahar, A., Peterson, S. and Taylor, D. (1996) Managing Training and Development in Bahrain: the Influence of Culture. Journal of Managerial Psychology, 11, 26-32. http://dx.doi.org/10.1108/02683949610124799

[11] Taylor, D. (1996) Training and Developing People. In: Molander, C., Ed., Human Resource at Work, Chartwell Bratt, London.

[12] Abdalla, I. and Al-Homoud, M. (1995) A Survey of Management Training and Development Practices in the State of Kuwait. Journal of Management Development, 14, 14-25. http://dx.doi.org/10.1108/02621719510078939

[13] Wilkins, S. (2001) Management Development in the Arab Gulf States: The Influence of Language and Culture. Industrial and Commercial Training, 33, 260-266. http://dx.doi.org/10.1108/00197850110409032

[14] Altarawneh, I. (2011) Training and Development Effectiveness. LAP Lambert Academic Publishing, SaarbrÜcken.

[15] Abdalla, H., Maghrabi, A. and Raggad, B. (1998) Assessing the Perceptions of Human Resource Managers toward Nepotism: A Cross-Cultural Study. International Journal of Manpower, 19, 554-570. http://dx.doi.org/10.1108/01437729810242235

[16] Agnaia, A. (1996) Assessment of Management Training Needs and Selection for Training: The Case of Libyan Companies. International Journal of Manpower, 17, 31-51. http://dx.doi.org/10.1108/01437729610119504

[17] Eastgate, M. (2000) Business Profit through People. Industrial and Commercial Training, 32, 161-163. http://dx.doi.org/10.1108/00197850010345782

[18] Burrow, J. and Berardinelli, P. (2003) Systematic Performance Improvement-Refining the Space between Learning and Results. Journal of Workplace Learning, 15, 6-13. http://dx.doi.org/10.1108/13665620310458776

[19] Redshaw, B. (2000) Evaluating Organizational Effectiveness. Industrial and Commercial Training, 32, 245-248. http://dx.doi.org/10.1108/00197850010379794

[20] McCarthy, A., Garavan, N. and O’Toole, T. (2003) HRD: Working at the Boundaries and Interfaces of Organizations. Journal of European Industrial Training, 4, 58-72. http://dx.doi.org/10.1108/03090590310468886

[21] Stone, R. (2002) Human Resource Management. 4th Edition, Wiley Art Department, Milton, Australia.

[22] Goldstein, I. (1993) Training in Organization: Needs Assessment, Development, and Evaluation. 3rd Edition, Brooks/ Cole Publishing Company, Pacific Grove.

[23] Beardwell, I. and Holden, L. (1994) Human Resource Management: A Contemporary Perspective. Pitman Publishing, London.

[24] Nadler, L. (1990) The Handbook of Human Resource Development. 2nd Edition, Wiley, New York and Chichester.

[25] Armstrong, M. (2003) A Handbook of Personnel Management Practice. 9th Edition, Kogan Page Limited, London.

[26] Rogers, W. and Wright, M. (1998) Measuring Organizational Performance in Strategic Human Resource Management: Problems, Prospects, and Performance Information Markets. Human Resource Management Review, 8, 311-331. http://dx.doi.org/10.1016/S1053-4822(98)90007-9

[27] Werther, J. and Davis, K. (1996) Human Resources and Personnel Management. 5th Edition, McGraw-Hill, New York.

[28] Reid, M. and Barrington, H. (1997) Training Intervention. 5th Edition, The Cromwell Press, Wiltshire.

[29] Harrison, R. (1997) Employee Development. Institute of Personnel and Development, London. 
[30] Marchington, M. and Wilkinson, A. (2000) People Management and Development. 2nd Edition, Chartered Institute of Personnel and Development, London.

[31] Latham, G. and Wexley, K. (1991) Developing and Training Human Resources in Organization. Harper Collins Publishers, New York.

[32] David, W.C. (2000) University School Collaboration and Needs Assessment in the Training of Student Leadership and Peer Support in Hong Kong. Roeper Review, 22, 263-266.

[33] Albahussain, A. (2000) Human Resource Development: An Investigation into the Nature and Extent of Training and Development in the Saudi Private Manufacturing. Unpublished PhD Thesis, Bradford University, Bradford.

[34] Luoma, M. (2000) Developing People for Business Success: Capability-Driven HRD in Practice. Management Decision, 38, 145-153. http://dx.doi.org/10.1108/EUM0000000005342

[35] Tao, Y.-H., Yeh, R. and Sun, S.-I. (2006) Improving Training Needs Assessment Processes via the Internet: System Design and Qualitative Study. Internet Research, 16, 427-449. http://dx.doi.org/10.1108/10662240610690043

[36] Lucier, K.H. (2008) A Consultative Training Program: Collateral Effect of a Needs Assessment. Communication Education, 57, 482-489.

[37] Gómez, P., Lorente, J. and Cabrera, R. (2010) Training Practices and Organizational Learning Capability: Relationship and Implications. Journal of European Industrial Training, 28, 234-256.

[38] Al-Ali, A. (1999) Human Resource Development Training and Development Practices and Related Organizational Factors in Kuwaiti Organizations. Unpublished PhD Thesis, Bradford University, Bradford.

[39] Al-Athari, A. (2000) The Impact of Multimedia Based Training on Employee Training Effectiveness and Organizational Performance. Unpublished PhD Thesis, Bradford University, Bradford.

[40] Al-Athari, A. and Zairi, M. (2002) Training Evaluation: An Empirical Study in Kuwait. Journal of European Industrial Training, 26, 241-251. http://dx.doi.org/10.1108/03090590210424911

[41] Bee, F. and Bee, R. (1994) Training Needs Analysis and Evaluation. Institute of Personnel Management, London.

[42] Read, C. and Kleiner, B. (1996) Which Training Methods Are Effective? Management Development Review, 9, $24-29$. http://dx.doi.org/10.1108/09622519610111781

[43] Al-Tarawneh, I. (2010) Human Resource Management Barriers: The Case of Jordanian Companies. Mu'tah Journal for Research and Studies University of Mu'tah, 25, 1-23.

[44] Motwani, G., Frahm, M. and Kathawala, Y. (1994) Achieving a Competitive Advantage through Quality Training. Training for Quality, 2, 35-40. http://dx.doi.org/10.1108/09684879410056229

[45] Acton, T. and Golden, W. (2003) Training the Knowledge Worker: A Descriptive Study of Training Practices in Irish Software Companies. Journal of European Industrial Training, 27, 137-146. http://dx.doi.org/10.1108/03090590310468958 